\title{
Produtividade e exportação de nutrientes em beterraba cultivada com cobertura morta e adubação orgânica
}

\author{
Maria A. N. Sediyama $^{1}$, Marlei R. Santos ${ }^{1}$, Sanzio M. Vidigal ${ }^{1} \&$ Luís T. Salgado $^{1}$
}

\section{RESU M 0}

O bjetivou-se, com este trabalho, avaliar o efeito da cobertura do solo e doses de lodo de lagoa de decantação de água residuária de suinocultura na produtividade e na exportação de nutrientes pela beterraba, cultivar Early Wonder. 0 experimento foi conduzido na Fazenda Experimental Vale do Piranga, pertencente à EPAMIG, Zona da Mata, em Oratórios, MG, no período de 07/08/08 a 09/11/08, no delineamento de blocos casualizados em parcelas subdivididas com quatro repetições. $N$ as parcelas foram dispostos três tipos de cobertura de solo: bagaço de cana-de-açúcar, palha de café e sem cobertura e, nas subparcelas, foram usadas cinco doses do lodo de lagoa: 0; 10; 20; 40 e 60 tha-1. Aos 70 dias após o transplante das mudas realizou-se a colheita. A cobertura com palha de café proporcionou maior massa unitária de raiz e maior produtividade de raízes comerciais, independente das doses de lodo. Os nutrientes mais exportados pela parte aérea das plantas foram $\mathrm{Ca}, \mathrm{Mg}$ e $\mathrm{S}$ e, pelas raízes, $\mathrm{N}, \mathrm{P}$ e $\mathrm{K}$. Com a população de 400.000 plantas ha-1 e produtividade de $34,22 \mathrm{tha}^{-1}$, as quantidades médias de $\mathrm{N}, \mathrm{P}, \mathrm{K}$, $\mathrm{Ca}, \mathrm{Mg}$ e S exportadas pelas raízes foram 140; 24; 180; 8, 17 e $5 \mathrm{~kg} \mathrm{ha}^{-1} \mathrm{e}$, para Zn, Fe, M n, Cu e B, 371, $435,320,74$ e $250 \mathrm{~g} \mathrm{ha}^{-1}$, respectivamente.

Palavras-chave: Beta vulgaris, cobertura do solo, produtividade, dejeto de suíno, lodo

\section{Yield and nutrient export of sugar beet under mulching and organic fertilization}

\begin{abstract}
A B STRACT
This work aimed to evaluate the effect of soil cover and doses of sludge from sedimentation pond of swine wastewater on yield and nutrient export in sugar beet cultivar Early W onder. The experiment was conducted at the Vale do Piranga Experimental Farm belonging to EPAM IG Zona da M ata in O ratórios (MG), from 07/08/08 to 09/11/08. The experiment was arranged in a split-plot in randomized block design with four replications. The main plots consisted of three types of mulching: sugarcane bagasse, coffee husk and without any cover, and the subplots of five doses of sludge: $0,10,20,40$ and $60 \mathrm{t} \mathrm{ha}^{-1}$. At 70 days after transplanting, harvest was carried out. Mulching with coffee husk provided the highest root unit weight and increased yield of commercial roots, independent of the sludge dose. The most exported nutrients by the shoots were $\mathrm{Ca}, \mathrm{Mg}$ and $\mathrm{S}$, while $\mathrm{N}, \mathrm{P}$ and $\mathrm{K}$ were the most exported by the roots. With a population of 400,000 plants ha-1 and yield of $34.22 \mathrm{t} \mathrm{ha}^{-1}$, the mean quantities of $\mathrm{N}, \mathrm{P}, \mathrm{K}$, $\mathrm{Ca}, \mathrm{Mg}$ and S exported by the roots were 140, 24, 180, 8, 17 and $5 \mathrm{~kg} \mathrm{ha}^{-1}$ and 371, 435, 320, 74 and $250 \mathrm{~g} \mathrm{ha}^{-1}$ of $\mathrm{Zn}, \mathrm{Fe}, \mathrm{Mn}, \mathrm{Cu}$ and $\mathrm{B}$ respectively.
\end{abstract}

Key words: Beta vulgaris, soil cover, yield, organic manure, swine manure, sludge 


\section{INTRODUÇÃO}

A beterraba (Beta vulgaris) é uma hortaliça que vem ganhando espaço e importância econômica no Brasil sendo, atualmente, uma das dez principais olerícolas produzidas no País. As raízes se caracterizam pelo sabor adocicado e coloração vermelha, devido à presença de betalaínas, substância antioxidante imprescindível na dieta humana (Kanner et al., 2001), além do alto valor nutricional e conteúdo de vitaminas e minerais, como K, Na, Fe, Cu e Zn (Ferreira \& Tivelli, 1990). Ela se destaca como uma das hortaliças mais ricas em ferro, tanto nas raízes quanto nas folhas. As plantas apresentam alto potencial de produção, atingindo rendimentos entre 25 a 40 t ha ${ }^{-1}$ de raízes (Horta et al., 2004; Grangeiro et al., 2007; Carvalho \& Guzzo, 2008).

Em áreas de horticultura o solo é constantemente preparado para permitir o estabelecimento rápido das plantas e reduzir a competição de plantas daninhas. O uso da cobertura morta envolvendo diferentes resíduos orgânicos traz vários benefícios aos sistemas de produção, especialmente no que diz respeito ao manejo do solo e das plantas (Pereira et al., 2000; Resende et al., 2005). Dentre as vantagens decorrentes de sua utilização pode-se destacar: retenção de umidade, melhoria da estrutura e menor compactação do solo (Corrêa, 2002), prevenção à erosão (Smolikowski et al., 2001) e aporte de matéria orgânica e nutrientes (Cadavid et al., 1998). Na cultura da beterraba a cobertura morta é pouco estudada; entretanto, é uma prática promissora, sobretudo em sistemas de cultivo orgânico, como forma de controlar a emergência de plantas daninhas, em razão das restrições de uso de produtos químicos (Resende et al., 2005). Entre os materiais orgânicos usados pode-se citar a palha de café (Sediyama et al., 2010), palha de arroz (Resende et al., 2005), bagaço de cana-de-açúcar triturado (Sediyama et al., 2010), capim gordura seco e serragem (Tozani et al., 2006) considerada prática de baixo custo e de fácil execução (Resende et al., 2005).

Considerando-se o potencial da atividade suinícola e a grande disponibilidade de dejeto de suínos na região do Vale do Piranga, na Zona da Mata mineira, formas de utilização desses resíduos têm sido investigadas como alternativa econômica para o produtor rural, na melhoria dos sistemas de produção, sem comprometer o meio ambiente, especialmente quando esses são devidamente tratados (Sediyama et al., 2008). Uma das maneiras de se tratar a água residuária, em especial nas pequenas suinoculturas, é por meio de lagoas de decantação que se separam as fases sólida e líquida. A fase sólida (lodo) se acumula no fundo da lagoa mesmo que, após longo tempo de permanência seja retirado; depois de secado ou compostado pode ser usado como fertilizante orgânico. A fase líquida é tratada em sistema de lagoas em série, para redução da carga e retorno aos mananciais de água.

A beterraba é considerada cultura esgotante do solo em razão da considerável remoção de massa verde do campo por ocasião das colheitas, visto que parte da produção é comercializada em maços com folhas, o que valoriza o produto mas retira da área todo o resto da cultura. Outra parte das raízes é embalada em caixas tipo K, sem a folhagem. Assim, o conhecimento do balanço de nutrientes, traduzido pela diferença entre a entrada dos elementos via adubação e a sua exportação nos produtos colhidos, é essencial para se manejar a adubação ao longo dos anos (Salgado et al., 1998).

São raras, na literatura, informações sobre a exigência nutricional da beterraba, sendo oportuno o conhecimento quanto ao total de nutrientes extraídos pela cultura, para definição de programas de adubação. Haag \& Minami (1987) verificaram, trabalhando com a cultivar Early Wonder, aumentos na produção de massa seca de parte aérea e raízes, até o final do ciclo, 80 dias após a semeadura. Para uma população de 330.000 plantas ha ${ }^{-1}$ a quantidade total extraída de nutrientes, em kg ha-1, foi de 30 de N; 8 de P; 75 de K; 2 de Ca e 4 de $\mathrm{Mg}$, enquanto Grangeiro et al. (2007) constataram, para a mesma cultivar e população semelhante, as quantidades totais em $\mathrm{kg} \mathrm{ha}^{-1}$ : 88 de N; 6,1 de P; 93,2 de K; 12,1 de Ca e 16,8 de Mg.

É importante considerar que a elevação dos teores de metais pesados nos alimentos vem sendo associada à aplicação de corretivos e fertilizantes, uso de água contaminada ou de produtos como lodo de esgoto, compostos de lixo urbano e resíduos diversos de indústria ou mineração. Uma vez nos solos agrícolas, esses elementos podem ser absorvidos pelas plantas, que fazem parte da alimentação humana ou animal. A legislação brasileira, seja a ambiental ou a referente aos aspectos sanitários alimentares, é pouco contundente com relação aos limites permitidos de metais pesados em solos, águas e alimentos. Existe grande carência de dados nacionais que subsidiem os legisladores e órgãos ambientais sendo, muitas vezes, utilizados valores limites verificados e utilizados em outros países (Fernandes et al., 2007).

Sampaio et al. (2008) verificaram aumento nos teores de Zn e $\mathrm{Cu}$ com a quantidade de argila do solo e na massa fresca e seca de raízes de beterraba com incremento na dose de composto de lixo urbano, que atingiu valores máximos com $90 \mathrm{t} \mathrm{ha}^{-1}$. Os teores de metais pesados nas raízes diminuíram com o aumento das doses de composto aplicadas devido, possivelmente, ao incremento de matéria orgânica do solo que atua como imobilizador e regulador da disponibilidade de metais pesados para as plantas.

Considerando o sistema de sucessão das hortaliças devido aos ciclos relativamente curtos e à demanda por grandes quantidades de fertilizantes orgânicos, tornam-se importantes estudos que contemplem a qualidade e a quantidade de adubos orgânicos aplicados. Objetivou-se, com este trabalho, avaliar o efeito da cobertura do solo com palha de café ou bagaço de cana-de-açúcar e doses de lodo de lagoa de decantação de água residuária de suinocultura na produtividade e na exportação de nutrientes, pela parte aérea e raízes de beterraba.

\section{Material E MÉTODOS}

O experimento foi conduzido na Fazenda Experimental Vale do Piranga pertencente à EPAMIG, Zona da Mata, em Oratórios, MG, no período de 07 de agosto a 09 de novembro de 2008. As coordenadas geográficas do local de execução do experimento são: latitude $20^{\circ} 30^{\prime} \mathrm{S}, 43^{\circ} 00^{\prime} \mathrm{O}$ e altitude $500 \mathrm{~m}$. As variáveis metereológicas são: temperatura média máxima anual de 21,8 ${ }^{\circ} \mathrm{C}$ e mínima anual de $19,5^{\circ} \mathrm{C}$ e a precipitação média anual de 
$1.250 \mathrm{~mm}$. Segundo Köppen, o clima da região varia do tipo Cwa, tropical úmido a Aw, semi-úmido de verões quentes e vegetação natural de floresta tropical semidecidual ou ombrofila mista (Cunha et al., 2000).

O Argissolo Vermelho-Amarelo câmbico, fase terraço apresentou, na camada de 0 a $20 \mathrm{~cm}$, as seguintes características: $\mathrm{pH}$ (água 1:2,5) =6,0; matéria orgânica $=16 \mathrm{~g} \mathrm{~kg}^{-1} ; \mathrm{P}=17,2$ $\mathrm{mg} \mathrm{dm}{ }^{-3} ; \mathrm{K}=178 \mathrm{mg} \mathrm{dm}^{-3} \mathrm{e}$ expressos em $\mathrm{cmol}_{\mathrm{c}} \mathrm{dm}^{-3}, \mathrm{Ca}^{2+}=2,9$; $\mathrm{Mg}^{2+}=0,9 ; \mathrm{Al}^{3+}=0,0 ; \mathrm{CTC}(\mathrm{t})=4,26 ; \mathrm{CTC}(\mathrm{T})=6,90, \mathrm{~V}=62 \%$ e P-rem $=35,6 \mathrm{mg} \mathrm{L}^{-1}$.

$\mathrm{O}$ delineamento experimental adotado foi em blocos casualizados e os tratamentos foram distribuídos em parcelas subdivididas com quatro repetições e 400 plantas por parcela. Nas parcelas foram dispostos três tipos de cobertura de solo: bagaço de cana-de-açúcar, palha de café e sem cobertura. Nas subparcelas foram aplicadas cinco doses $(0 ; 10 ; 20 ; 40$ e $60 \mathrm{t}$ ha $^{-1}$ ) de lodo de lagoa de decantação de águas residuárias de suinocultura. As parcelas foram constituídas de canteiros com $1 \mathrm{~m}$ de largura e $10 \mathrm{~m}$ de comprimento. Cada subparcela $(2 \times 1 \mathrm{~m})$ foi composta de quatro fileiras de plantas no espaçamento de $0,25 \times 0,10 \mathrm{~m}$, sendo a área útil de $0,8 \mathrm{~m}^{2}$ central. Após o preparo dos canteiros as doses de lodo foram aplicadas a lanço, em área total, e incorporadas, com enxada, na profundidade de 0 a $15 \mathrm{~cm}$; depois, a superfície do canteiro foi coberta com uma camada de aproximadamente $2 \mathrm{~cm}$ de espessura, equivalente a $10 \mathrm{t} \mathrm{ha}^{-1}$ de bagaço de cana-de-açúcar triturado ou palha de café. As características dos resíduos orgânicos e do lodo se encontram na Tabela 1.

Tabela 1. Características químicas e físicas da palha de café, do bagaço de cana-de-açúcar e do lo do de lagoa de decantação de águas resi duárias de suinocultura

\begin{tabular}{|c|c|c|c|}
\hline Características & $\begin{array}{l}\text { Palha } \\
\text { de café }\end{array}$ & $\begin{array}{c}\text { Bagaço de } \\
\text { cana-de-açúcar }\end{array}$ & $\begin{array}{l}\text { Lodo } \\
\text { de lagoa }\end{array}$ \\
\hline$N\left(g_{k g}^{-1}\right)$ & 23,50 & 2,00 & 9,00 \\
\hline$P "$ & 1,30 & 0,40 & 42,00 \\
\hline K" & 48,00 & 1,60 & 2,40 \\
\hline $\mathrm{Ca} "$ & 10,80 & 1,70 & 132,00 \\
\hline $\mathrm{Mg} "$ & 1,20 & 0,20 & 4,20 \\
\hline$S^{\prime \prime}$ & 1,20 & 0,10 & 4,40 \\
\hline $\mathrm{Zn}\left(\mathrm{mg} \mathrm{kg}^{-1}\right)$ & 31,00 & 9,00 & 1359,00 \\
\hline $\mathrm{Fe} "$ & 925,00 & 1082,00 & 6187,00 \\
\hline$M n "$ & 139,00 & 73,00 & 1364,00 \\
\hline $\mathrm{Cu} "$ & 27,00 & 1,00 & 573,00 \\
\hline B " & 22,40 & 13,10 & 12,00 \\
\hline Densidade $\left(\mathrm{kg} \mathrm{dm}^{-3}\right)$ & 0,12 & 0,05 & 0,82 \\
\hline Umidade (\%) & 10,00 & 9,80 & 38,20 \\
\hline $\mathrm{C} / \mathrm{N}$ & 11,50 & 132,00 & 2,42 \\
\hline $\mathrm{pH}$ & 6,70 & 5,90 & 7,00 \\
\hline
\end{tabular}

As mudas de beterraba, cultivar Early Wonder, foram produzidas em bandejas de poliestireno expandido com 200 células, preenchidas com substrato produzido à base de vermicomposto de esterco bovino e transplantadas com 20 dias de idade e 21 dias após a aplicação do lodo. A irrigação foi realizada por microaspersão, com turno de rega de dois dias; logo após o transplante das mudas observou-se o ataque da lagarta-rosca (Agrotis ipsilon), em alguns tratamentos, cujo controle foi feito com aplicação do inseticida biológico Dipel.
A colheita foi realizada manualmente aos 70 dias após o transplantio das mudas, quando a maioria das raízes tuberosas apresentava, visualmente, o tamanho preferido para o mercado, ou seja, raízes entre 200 a 300 g. Quando da colheita avaliouse, na área útil, a altura média de 10 plantas, contou-se o número de plantas por subparcela e se pesou a massa fresca total das raízes e da parte aérea. As raízes foram classificadas, quanto ao calibre, em comercial (classes 50, 90 e 120 mm) e não comercial (refugo, raízes com defeitos graves e ocorrência de praga), de acordo com Hortbrasil (2006). As classes comerciais: classe 50 (maior ou igual a $50 \mathrm{e}<90 \mathrm{~mm}$ ); classe 90 (maior ou igual a $90 \mathrm{e}$ $<120 \mathrm{~mm}$ ) e classe 120 (> $120 \mathrm{~mm})$ e refugo (<50 mm); calculouse, também, a massa fresca unitária de raízes comerciais.

Amostras de raízes comerciais de cada tratamento foram lavadas e secadas ao ar, cortadas ao meio e raladas em ralador inox, para determinação do teor de sólidos solúveis (Brix) no extrato, por meio de um refratômetro digital, Atago, modelo PR101 (escala 0-45\%), ajustado, em temperatura de $25^{\circ} \mathrm{C}$. Amostras da parte aérea e das raízes foram coletadas, pesadas, colocadas em sacos de papel e levadas para secagem em estufa com circulação de ar forçada, a temperatura de $65^{\circ} \mathrm{C}$, por $72 \mathrm{~h}$. As amostras de raiz foram lavadas previamente, secadas ao ar e cortadas em cubos para facilitar a moagem do material seco. Após a determinação da massa seca da parte aérea (pecíolo e limbo das folhas) e das raízes, os materiais foram moídos em moinho tipo Willey, colocados em saquinhos de papel e levados ao laboratório para análise de $\mathrm{N}, \mathrm{P}, \mathrm{K}, \mathrm{Ca}, \mathrm{Mg}, \mathrm{S}, \mathrm{Fe}, \mathrm{Cu}, \mathrm{Zn}$, Mn e B. A quantificação dos nutrientes foi feita nos extratos obtidos pela digestão nítrico-perclórica $(\mathrm{P}, \mathrm{K}, \mathrm{Ca}, \mathrm{Mg}, \mathrm{S}, \mathrm{Fe}$, $\mathrm{Cu}, \mathrm{Zn}$ e $\mathrm{Mn}$ ), sendo o $\mathrm{P}$ pelo método da vitamina $\mathrm{C}$; o $\mathrm{K}$, pela fotometria de chama; $\mathrm{Ca}, \mathrm{Mg}, \mathrm{Fe}, \mathrm{Cu}, \mathrm{Zn}$ e $\mathrm{Mn}$ por espectrofotometria de absorção atômica; o $\mathrm{N}$ foi quantificado pelo método semimicro Kjeldahl e o boro por digestão seca, por meio de incineração da amostra em mufla elétrica a $550^{\circ} \mathrm{C}$, utilizando-se o método da azometina- $\mathrm{H}$, conforme descrito em Malavolta et al. (1997). Com base na massa seca da parte aérea e das raízes das plantas por hectare e nos teores de nutrientes, calculou-se seu acúmulo nessas frações.

Os dados obtidos foram submetidos à análise de variância (teste de F) e de regressão, quando significativos; a comparação entre médias foi feita pelo teste de Tukey $(\mathrm{P}<0,05)$ utilizandose o software SAEG.

\section{RESULTADOS E DISCUSSÃO}

Não houve interação para cobertura morta nem doses de lodo para as características avaliadas, mas ocorreu efeito para tipos de cobertura morta. A cobertura com palha de café apresentou menor número de plantas de beterraba $(26,05)$ na subparcela $\left(0,8 \mathrm{~m}^{2}\right)$, em relação ao tratamento sem cobertura morta $(28,65)$, porém ambos não diferiram do tratamento com bagaço de cana-de-açúcar (Tabela 2). Este fato pode estar relacionado com o dano causado pela lagarta-rosca (Agrotis ipsilon) no tratamento com palha de café, logo após o transplantio das mudas, com perda de plantas e necessidade de replantio devido, provavelmente, à umidade no solo, condição preferida pela lagarta rosca, além de maior proteção 
Tabela 2. N úmero de plantas por subparcela (NP)*, al tura média de plantas (AP), massa fresca por planta por subparcela (M FPA), massa seca da parte aérea (M SPA), massa unitária da raiz (MUR), produtividade de raízes comerciais (PRC) e massa seca de raízes (MSR) de beterraba cultivada com três tipos de cobertura do solo e cinco doses de lodo de lagoa de decantação de águas residuárias de suinocultura

\begin{tabular}{|c|c|c|c|c|c|c|c|}
\hline Cobertura & $\begin{array}{l}\text { NP } \\
\text { (ud) }\end{array}$ & $\begin{array}{l}\text { AP } \\
(\mathrm{cm})\end{array}$ & $\begin{array}{c}\text { MF PA } \\
{\text { (g } \text { planta }^{-1} \text { ) }}^{\text {M }}\end{array}$ & $\begin{array}{c}\text { MSPA } \\
(\%)\end{array}$ & $\begin{array}{l}\text { MUR } \\
\text { (g) }\end{array}$ & $\begin{array}{c}\text { PRC } \\
\left(t \text { ha }^{-1}\right)\end{array}$ & $\begin{array}{c}\text { MSR } \\
(\%)\end{array}$ \\
\hline $\begin{array}{l}\text { Sem cobertura } \\
\text { Palha de café } \\
\text { Bagaço de cana } \\
\text { Médias }\end{array}$ & $\begin{array}{l}28,65 a \\
26,05 b \\
27,00 a b \\
27,23\end{array}$ & $\begin{array}{l}50,13 a \\
50,08 a \\
46,19 \mathrm{~b} \\
48,80\end{array}$ & $\begin{array}{r}80,89 \mathrm{~b} \\
102,90 \mathrm{a} \\
84,59 \mathrm{~b} \\
89,46\end{array}$ & $\begin{array}{l}8,52 a \\
8,11 a \\
8,49 a \\
8,37\end{array}$ & $\begin{array}{l}207,33 \mathrm{~b} \\
293,85 a \\
233,85 a b \\
245,01\end{array}$ & $\begin{array}{l}32,15 b \\
38,66 a \\
31,84 b \\
34,22\end{array}$ & $\begin{array}{l}14,18 \mathrm{a} \\
12,61 \mathrm{~b} \\
13,13 \mathrm{~b} \\
13,30\end{array}$ \\
\hline CV (\%) & 10,02 & 5,59 & 17,33 & 6,55 & 34,47 & 19,70 & 8,80 \\
\hline
\end{tabular}

Médias seguidas da mesma letra minúscula não diferem entre si a $5 \%$ de probabilidade, pelo teste Tukey.

A área útil da subparcela é $0,8 \mathrm{~m}^{2}$

dos insetos pela barreira física ao inseticida Dipel. Redução significativa no estande de plantas em razão da ocorrência de lagarta rosca, também foi constatada no sistema de plantio direto, em regiões produtoras de feijão, em virtude da maior cobertura do solo pela palhada (Quintela, 2005).

A cobertura com bagaço de cana-de-açúcar proporcionou menor altura de plantas em relação à cobertura com palha de café e ausência de cobertura do solo devido, sem dúvida, à lenta decomposição do material e à menor quantidade de nutrientes disponíveis para a cultura. A cobertura morta com materiais orgânicos com alta relação $\mathrm{C} / \mathrm{N}$ pode prejudicar o desenvolvimento das plantas quanto à deficiência de $\mathrm{N}$ no solo. A baixa concentração de $\mathrm{N}$ dos resíduos vegetais (relação $\mathrm{C} / \mathrm{N}$ alta) promove a imobilização do $\mathrm{N}$ mineral disponível no solo para atender à demanda dos micro-organismos no processo de decomposição, comprometendo a nutrição nitrogenada das lavouras (Robinson, 1988; Calvo et al., 2010).

Maior produção de massa fresca da parte aérea foi obtida no tratamento com palha de café em relação ao bagaço de cana-de-açúcar e solo sem cobertura, enquanto a porcentagem de massa seca de parte aérea não diferiu entre os tipos de cobertura morta (Tabela 2).

A maior massa unitária média de raiz (293,85 g) ocorreu no tratamento com palha de café em relação ao tratamento sem cobertura, porém sem diferir do tratamento com bagaço de canade-açúcar (Tabela 2). Não houve diferença estatística entre tratamentos para as diferentes classes de raíz. Maior concentração de raízes comerciais ocorreu na classe compreendida entre 50 a $90 \mathrm{~mm}(85,4 \%)$, seguida da classe 90 a $120 \mathrm{~mm}(14,6 \%)$ e não houve produção de raízes maiores que $120 \mathrm{~mm}$.

Obteve-se maior produtividade de raízes comerciais (38,66 $\left.\mathrm{t} \mathrm{ha}^{-1}\right)$ com palha de café, diferindo significativamente da cobertura com bagaço de cana-de-açúcar e do tratamento sem cobertura (Tabela 2). Esses resultados podem ser atribuídos ao maior fornecimento de nutrientes pela palha de café em decorrência de sua composição química, maior facilidade de decomposição pela menor relação $\mathrm{C} / \mathrm{N}$ (Tabela 1). Tal hipótese pode ser sustentada pela maior produção de massa fresca da parte aérea, maior massa unitária de raiz e pela maior produtividade de raízes comerciais nos tratamentos com palha de café em relação aos tratamentos sem cobertura morta e cobertura com bagaço de cana-de-açúcar. A maior porcentagem de massa seca de raízes comerciais foi obtida no tratamento sem cobertura morta, ou seja, no tratamento com menor massa unitária de raízes (Tabela 2); assim, raízes menores apresentaram mais massa seca.

As produtividades obtidas se mantiveram entre $30 \mathrm{a} 40 \mathrm{t} \mathrm{ha}^{-1}$, em que todos os tipos de cobertura apresentaram altas produções de raízes com qualidade comercial e dentro da média brasileira (20 a $35 \mathrm{t} \mathrm{ha}^{-1}$ ). Esses resultados se diferenciam daqueles obtidos por Tozani et al. (2006), que avaliaram o controle de plantas daninhas em beterraba com cobertura morta de capim gordura e Jaraguá, nas quantidades de 2, 4 e $6 \mathrm{~kg} \mathrm{~m}$ ${ }^{2}$ aplicadas após a emergência, capim gordura $\left(4 \mathrm{~kg} \mathrm{~m}^{-2}\right)$ após a semeadura, além do plástico preto, controle químico (herbicida EPTC) e testemunhas com e sem capina, e verificaram que todos os tratamentos reduziram o peso unitário e a produção de raízes em relação à testemunha com capina manual, que produziu $15,1 \mathrm{t} \mathrm{ha}^{-1}$. A baixa produtividade de raízes encontrada por Tozani et al. (2006), pode ser atribuída às condições do solo e do local de plantio.

Apesar de praticamente não haver pesquisas envolvendo cobertura de solo no cultivo de beterraba, de acordo com os resultados obtidos neste trabalho e em outros, como na cenoura (Resende et al., 2005) e na alface (Carvalho et al., 2005), o uso da cobertura morta pode ser uma estratégia interessante para a produção da cultura, especialmente na agricultura familiar, porém se deve atentar para a espessura da camada, sobretudo quando se faz semeadura diretamente nos canteiros, e pelo tipo de cobertura morta, pois materiais orgânicos de alta relação $\mathrm{C} / \mathrm{N}$ podem prejudicar a cultura se não forem tomados alguns cuidados, como adição de $\mathrm{N}$, por via orgânica ou mineral. Puiatti et al. (1992) estudaram, no taro 'Chinês', a viabilidade do uso de bagaço de cana-de-açúcar e capim gordura, empregados em diferentes sistemas (em cobertura, sulco de plantio e sulco mais cobertura) associados ou não ao $\mathrm{N}$, e concluíram que o uso desses resíduos proporcionou aumento significativo na produção de rizomas, quando associados à aplicação de $\mathrm{N}$.

Cobertura morta com resíduo orgânico de alta relação $\mathrm{C} / \mathrm{N}$ pode causar imobilização temporária durante o processo de decomposição (Calvo et al., 2010). Acredita-se que, neste contexto, resultados mais promissores quanto ao controle de plantas daninhas e produtividade de raízes de beterraba, poderiam ser conseguidos com a mistura da palha de café e bagaço de cana-de-açúcar (Sediyama et al., 2010). Resende et al. (2005) também verificaram vantagem na cobertura morta para o cultivo de verão da cenoura, reduzindo a temperatura em até 3,5 ${ }^{\circ} \mathrm{C}$ e aumentando a retenção de umidade do solo em até $2,3 \%$ em relação ao controle, com melhor desenvolvimento das plantas. 
Constatou-se correlação positiva entre massa fresca de parte aérea e massa fresca de raízes (comercial + refugo) para os tratamentos sem cobertura $(r=0,82)$, palha de café $(r=0,95)$ e bagaço de cana-de-açúcar $(r=0,89)$. A maior correlação massa fresca de parte aérea e massa fresca de raízes obtida no tratamento com palha de café se deve à maior altura das plantas e à maior produção de massa fresca de plantas, ou seja, maior parte aérea implica em maior área foliar e produção de fotoassimilados, consequência da melhor nutrição das plantas neste tratamento.

Não houve efeito de tratamentos para o teor de sólidos solúveis, obtendo-se valor médio de $8,61{ }^{\circ}$ Brix, valor este semelhante àqueles normalmente encontrados para a cultivar Early Wonder (Sanches et al., 2008; Marques et al., 2010). De modo geral, o potássio influencia os teores de sólidos solúveis, com o aumento nos teores de açúcar nas raízes de beterraba. Apesar do teor de K estar relativamente alto no solo e também na palha de café (Tabela 1) ele não foi suficiente para aumentar a concentração de sólidos solúveis nas raízes. De acordo com Sanches et al. (2008), nem sempre maior disponibilidade de K vai promover mudanças no teor de sólidos solúveis nas raízes de beterraba, seja pelo tipo de solo, clima ou cultivar, seja pela capacidade de utilização deste nutriente pelas plantas. Deste modo, o teor de sólidos solúveis parece ser uma característica inerente a cada cultivar, uma vez que Marques et al. (2010) não encontraram diferenças no teor de sólidos solúveis nem no pH das raízes de beterraba cultivada com diferentes doses de esterco bovino.

Houve interação entre tipos de cobertura e doses de lodo de lagoa para a produção de raízes não comercial. A cobertura com bagaço de cana-de-açúcar apresentou maior produção na dose de $20 \mathrm{t} \mathrm{ha}^{-1}$ de lodo e, no tratamento com palha de café, as maiores produções de raízes não comerciais ocorreram nas doses de 40 e 60 t ha $^{-1}$ de lodo de lagoa. Nos demais tratamentos não houve diferenças para dose de lodo nem tipo de cobertura (Tabela 3). Apesar de não haver diferenças para doses de lodo, a cobertura do solo com palha de café proporcionou maior massa fresca de parte aérea e de raízes comerciais (Tabela 2); assim, a maior produção de raízes não comerciais (refugo) pode estar relacionada à maior produção total de raízes, inclusive de raízes com defeitos graves ou pragas, que também foram incluídas no refugo.

Comumente, a falta de resposta para doses de lodo pode estar relacionada à baixa concentração de $\mathrm{N}$ no lodo (Tabela 1) e ao teor de matéria orgânica no solo. Por ocasião da colheita, 70 dias após o transplante, o acúmulo de massa seca das raízes correspondeu a $74,9 \%$ da massa seca da planta.

Visto que não houve diferenças entre doses de lodo para produtividade de massa fresca de parte aérea e de raízes de beterraba, as análises de nutrientes em tecidos de parte aérea e raízes e o estudo de exportação foram realizados e quantificados apenas na maior dose do lodo $\left(60 \mathrm{t} \mathrm{ha}^{-1}\right)$. Neste tratamento observou-se maior acúmulo de $\mathrm{Ca}, \mathrm{Mg}$ e $\mathrm{S}$ na parte aérea das plantas enquanto N, P e K se acumularam, preferencialmente, nas raízes. $\mathrm{O}$ acúmulo de $\mathrm{Fe}$ e $\mathrm{Mn}$ foi maior na parte aérea e $\mathrm{Zn}$, $\mathrm{Cu}$ e B foi maior nas raízes (Tabela 4).

Ressalta-se a concentração de $\mathrm{Cu}$ e $\mathrm{Zn}$ nos resíduos orgânicos e nas plantas (folhas e raízes), pelo fato de serem micronutrientes do grupo dos metais, com importante papel na nutrição das plantas mas que, em altas concentrações, são

Tabela 3. Produção de raízes não comerciais de beterraba cultivada em três tipos de cobertura do solo e cinco doses de lodo de lagoa de decantação de águas residuárias de suinocultura

\begin{tabular}{|c|c|c|c|c|c|c|}
\hline \multirow{2}{*}{ Cobertura } & \multicolumn{5}{|c|}{ Doses de lodo (t ha-1) } & \multirow{2}{*}{ Médias } \\
\hline & 0 & 10 & 20 & 40 & 60 & \\
\hline Sem cobertura & $5,19 a A$ & $4,47 \mathrm{aA}$ & $6,25 \mathrm{bA}$ & $4,14 \mathrm{bA}$ & $2,94 \mathrm{bA}$ & 4,60 \\
\hline Palha de café & $6,38 \mathrm{aB}$ & $5,78 \mathrm{aB}$ & $3,02 \mathrm{bB}$ & $13,84 \mathrm{aA}$ & $6,92 \mathrm{aB}$ & 7,20 \\
\hline Bagaço de cana & $4,30 \mathrm{aB}$ & $4,30 \mathrm{aB}$ & $10,09 \mathrm{aA}$ & $3,06 \mathrm{bB}$ & $4,80 \mathrm{bB}$ & 5,31 \\
\hline Médias & 5,29 & 4,85 & 6,45 & 7,03 & 4,89 & \\
\hline C.V. (\%) & & & 63,84 & & & \\
\hline
\end{tabular}

Médias seguidas da mesma letra, maiúscula nas linhas e minúscula na coluna, não diferem entre si a $5 \%$ de probabilidade, pelo teste Tukey

Tabela 4. Exportação de nutrientes pela parte aérea e raiz de beterraba com aplicação da dose de 60 tha-1 de lodo de lagoa de decantação de água residuária de suinocultura e três tipos de cobertura do solo, palha de café (PC), bagaço de cana-de-açúcar (BC) e sem cobertura morta (SC)

\begin{tabular}{|c|c|c|c|c|c|c|}
\hline \multirow{2}{*}{ Nutrientes } & \multicolumn{3}{|c|}{ Parte Aérea } & \multicolumn{3}{|c|}{ Raiz } \\
\hline & PC & BC & SC & PC & $B C$ & SC \\
\hline & \multicolumn{6}{|c|}{$\mathrm{kg} \mathrm{ha}^{-1}$} \\
\hline $\mathrm{N}$ & 73,86 & 77,94 & 67,60 & 149,46 & 143,63 & 125,78 \\
\hline P & 9,90 & 11,02 & 9,66 & 25,45 & 24,68 & 21,54 \\
\hline K & 108,60 & 100,79 & 90,89 & 182,17 & 202,61 & 156,92 \\
\hline $\mathrm{Ca}$ & 43,22 & 37,39 & 28,43 & 8,04 & 7,72 & 8,13 \\
\hline $\mathrm{Mg}$ & 23,14 & 20,88 & 16,35 & 18,14 & 17,97 & 14,74 \\
\hline$S$ & 7,16 & 7,15 & 6,28 & 5,66 & 5,09 & 3,47 \\
\hline & \multicolumn{6}{|c|}{$g h^{-1}$} \\
\hline $\mathrm{Zn}$ & 271,65 & 309,71 & 260,26 & 384,99 & 357,61 & 371,38 \\
\hline $\mathrm{Fe}$ & 2465,56 & 2112,17 & 3135,66 & 423,01 & 528,50 & 353,66 \\
\hline$M n$ & 679,34 & 598,28 & 522,13 & 336,65 & 304,54 & 317,77 \\
\hline $\mathrm{Cu}$ & 36,30 & 36,47 & 39,74 & 81,18 & 70,24 & 71,48 \\
\hline B & 143,24 & 121,43 & 132,48 & 288,54 & 246,40 & 213,63 \\
\hline
\end{tabular}


considerados nocivos e cujas concentrações são influenciadas pela textura e pelo teor de matéria orgânica do solo (Sampaio et al., 2008). Quando o solo é fertilizado com adubos orgânicos ricos em $\mathrm{Cu}$ e $\mathrm{Zn}$, a liberação desses nutrientes ocorre à medida em que a matéria orgânica é decomposta e as plantas podem absorver esses nutrientes além do limite permitido para o consumo, especialmente se doses maiores de adubo orgânico forem utilizadas ou aplicações sucessivas forem feitas (Mesquita Filho et al., 2002).

No Brasil não existe, ainda, uma legislação federal que regulamenta a aplicação de lodo de esgoto ou lodo de lagoa de águas residuárias na agricultura. Os estados de São Paulo e Paraná definiram legislações para orientar o uso do lodo de esgoto, para as condições brasileiras (CETESB, 1999), cujas concentrações máximas de Cu eZn permitidas para uso agrícola nesses Estados são, respectivamente, 4300 e $7500 \mathrm{mg} \mathrm{kg}^{-1} \mathrm{e}$ 1000 e $2500 \mathrm{mg} \mathrm{kg}^{-1}$ na matéria seca. De acordo com a legislação, os teores de $\mathrm{Cu}\left(573 \mathrm{mg} \mathrm{kg}^{-1}\right)$ e Zn (1359 $\left.\mathrm{mg} \mathrm{kg}^{-1}\right)$ encontrados no lodo da lagoa de água residuária da suinocultura, estão abaixo do limite tolerado.

Considerando a taxa anual máxima de aplicação do lodo de esgoto ao solo em função do conteúdo em metais pesados, e a carga máxima de acúmulo de metais ao solo em função de alocações sucessivas do resíduo à CETESB (1999) prevêem-se os seguintes limites 75 e $140 \mathrm{~kg} \mathrm{ha}^{-1}$ ano $^{-1}$ e 1500 e $2800 \mathrm{~kg} \mathrm{ha}^{-1}$, para $\mathrm{Cu}$ e $\mathrm{Zn}$, respectivamente. Desta forma, é importante controlar a dosagem e a frequência de aplicação, para não exceder a quantidade acumulada no solo uma vez que, nas condições deste estudo, a maior dose utilizada foi $60 \mathrm{t} \mathrm{ha}^{-1} \mathrm{do}$ lodo, que forneceu cerca de $34,4 \mathrm{~kg} \mathrm{ha}^{-1}$ de $\mathrm{Cu}$ e $81,5 \mathrm{~kg} \mathrm{ha}^{-1} \mathrm{de}$ $\mathrm{Zn}$.

Em geral, o lodo de lagoa de decantação de águas residuárias da suinocultura não é usado na produção de hortaliças. Verificou-se, no entanto, que com uma única aplicação de $60 \mathrm{t}$ $\mathrm{ha}^{-1}$ do lodo os teores de nutrientes encontrados nas folhas e raízes de beterraba não extrapolaram os limites permitidos para consumo humano, especialmente para $\mathrm{Cu}\left(14,3 \mathrm{mg} \mathrm{kg}^{-1}\right)$ e $\mathrm{Zn}$ $\left(107,1 \mathrm{mg} \mathrm{kg}^{-1}\right)$ nas folhas e $\mathrm{Cu}\left(9,3 \mathrm{mg} \mathrm{kg}^{-1}\right)$ e $\mathrm{Zn}\left(46 \mathrm{mg} \mathrm{kg}^{-1}\right)$ nas raízes, conforme estabelecido pela legislação brasileira (ABIA, 1985). Os sistemas de produção que visam ao uso de resíduos orgânicos, como palhada e esterco de animais, podem economizar fertilizantes como P, K, Ca, Mg e micronutrientes, presentes nesses materiais; porém, considerando-se o ciclo relativamente curto das olerícolas e a frequência das aplicações, doses seguras ou adequadas devem ser recomendadas para evitar acúmulo de metais pesados nos solos, nos alimentos e na água.

A aplicação do lodo, sabidamente rico em Cu (573 $\left.\mathrm{mg} \mathrm{kg}^{-1}\right)$ e Zn (1359 $\left.\mathrm{mg} \mathrm{kg}^{-1}\right)$ proporcionou, na maior dose aplicada $(60 \mathrm{t}$ ha ${ }^{-1}$ ), exportação média de 74,3 e 371,32 $\mathrm{g} \mathrm{kg}^{-1}$ nas raízes de beterraba, respectivamente (Tabela 4). A quantidade total de nutrientes exportados pela parte aérea e raízes de beterraba foi maior nos tratamentos com cobertura morta, à exceção do Fe, que foi maior na testemunha sem cobertura (Tabela 4), devido, talvez, às melhores condições do solo com cobertura morta, favorecendo a absorção dos nutrientes pelas raízes.

$\mathrm{O} F$ fo foi o micronutriente mais exportado, sobretudo pela parte aérea (folhas + pecíolos), em consequência da alta concentração no lodo aliado ao fato da beterraba ser uma das hortaliças mais acumuladoras de Fe, tanto nas raízes quanto nas folhas (Ferreira \& Tivelli, 1990). Normalmente, as folhas apresentam maior concentração em relação às raízes; desta forma, folhas e pecíolos devem ser aproveitados na alimentação pois, além de conter vitamina A, possui ótima quantidade de fibras e minerais.

Em relação à média dos três tipos de cobertura do solo, população de 400.000 plantas ha ${ }^{-1}$ e produtividade média de $34,22 \mathrm{t} \mathrm{ha}^{-1}$, as quantidades de N, P, K, Ca, Mg e S exportadas pelas raízes foram 140; 24; 180; 8, 17 e $5 \mathrm{~kg} \mathrm{ha}^{-1}$ e para $\mathrm{Zn}, \mathrm{Fe}$, $\mathrm{Mn}, \mathrm{Cu}$ e B foram 371, 435, 320, 74 e $250 \mathrm{~g} \mathrm{ha}^{-1}$, respectivamente. Os valores médios de $\mathrm{N}, \mathrm{P}$ e $\mathrm{K}$ exportados pelas raízes de beterraba foram superiores aos encontrados por Grangeiro et al. (2007) para a mesma cultivar e população de plantas (88 de N, 6,1 de P, 93,2 de K, 12,1 de Ca e 16,8 de Mg, em kg ha ${ }^{-1}$ exportados pelas raízes). Apesar dessas diferenças os resultados fornecem informações importantes para o manejo da adubação, em termos dos nutrientes requeridos pelas plantas, uma vez que alguns fatores, como solo, variedade, clima e população de plantas, entre outros, podem alterar a absorção e a exportação de nutrientes.

\section{CONCLUSÕES}

1. A cobertura morta com palha de café proporcionou maior massa unitária de raiz e maior produtividade de raízes comerciais.

2. Os nutrientes mais exportados pela parte aérea das plantas, foram $\mathrm{Ca}, \mathrm{Mg}$ e $\mathrm{S}$ e, pelas raízes, $\mathrm{N}, \mathrm{P}$ e K.

3. A ordem de exportação dos macronutrientes foi $\mathrm{K}>\mathrm{N}>$ $\mathrm{Ca}>\mathrm{Mg}>\mathrm{P}>\mathrm{S}$ e dos micronutrientes, $\mathrm{Fe}>\mathrm{Mn}>\mathrm{Zn}>\mathrm{B}>\mathrm{Cu}$.

\section{Agradecimentos}

À Fundação de Amparo à Pesquisa do Estado de Minas Gerais (FAPEMIG) pelo auxílio financeiro do Programa Pesquisador Mineiro - PPM, e pelas bolsas BIPDT e PDJ e ao $\mathrm{CNPq}$, pela bolsa de produtividade em pesquisa.

\section{LITERATURA CITADA}

ABIA - Associação Brasileira das Indústrias da Alimentação. Compêndio da legislação dos alimentos. São Paulo: ABIA, 1985. 185p.

Cadavid, L. F.; El-Sharkawy, M. A.; Acosta, A.; Sánchez, T. Long-term effects of mulch, fertilization and tillage on cassava growth in sandy soils in Northern Colombia. Field Crops Research, v.57, p.45-56, 1998.

Calvo, C. L.; Foloni, J. S. S.; Brancalião, S. R. Produtividade de fitomassa e relação $\mathrm{C} / \mathrm{N}$ de monocultivos e consórcios de guandu-anão, milheto e sorgo em três épocas de corte. Bragantia, v.69, p.77-86, 2010.

Carvalho, J. E.; Zanella, F.; Mota, J. H.; Lima, A. L. S. Cobertura morta do solo no cultivo de alface cv. Regina 2000, em JiParaná/RO. Ciência e Agrotecnologia, v.29, p.935-939, 2005. 
Carvalho, L. B.; Guzzo, C. D. Adensamento da beterraba no manejo de plantas daninhas. Planta Daninha, v.26, p.73-82, 2008.

CETESB - Companhia Ambiental do Estado de São Paulo. Aplicação de lodos de sistemas de tratamento biológico em áreas agrícolas: Critérios para projeto e operação. São Paulo: 1999. 32p. Manual Técnico P 4.230.

Corrêa, J. C. Efeito de sistemas de cultivo na estabilidade de agregados de um Latossolo Vermelho-Amarelo em Querência, MT, Pesquisa Agropecuária Brasileira, v.37, p.203-209, 2002.

Cunha, T. J. F.; Blancaneaux, P.; Calderano Filho, B.; Carmo, C. A. F. S.; Garcia, N. C. P.; Lima, E. M. B. Influência da diferenciação pedológica no desenvolvimento da seringueira no município de Oratórios, MG. Pesquisa Agropecuária Brasileira, v.35, p.145-155, 2000.

Fernandes; R. B. A; Luz, W. V.; Fontes, M. P. F.; Fontes, L. E. F. Avaliação da concentração de metais pesados em áreas olerícolas no Estado de Minas Gerais. Revista Brasileira de Engenharia Agrícola e Ambiental, v.11, p.81-93, 2007.

Ferreira, M. D.; Tivelli, S. W. Cultura da beterraba: Recomendações gerais. 3.ed. Guaxupé: COOXUPÉ, 1990. 14p. Boletim Técnico Olericultura, 2.

Grangeiro, L. C.; Negreiros, M. Z.; Souza, B. S.; Azevedo, P. E.; Oliveira, S. L.; Medeiros, M. A. Acúmulo e exportação de nutrientes em beterraba. Ciência e Agrotecnologia, v.31, p.267-273, 2007.

Haag, H. P.; Minami, K. Nutrição mineral de hortaliças: LXIII requerimento de nutrientes pela cultura da beterraba. Anais da Escola Superior de Agricultura "Luiz de Queiroz", Piracicaba, v.44, p.401-407, 1987.

Horta, A. C. S.; Santos, H. S.; Constantin, J. Scapim, C. A. Interferência de plantas daninhas na beterraba transplantada e semeada diretamente. Acta Scientiarum Agronomy, v.26, p.47-53, 2004.

Hortibrasil - Centro de qualidade de horticultura - Norma de classificação da beterraba (Beta vulgaris L.). São Paulo: CQH/CEAGESP, 2006. <http://www.hortibrasil.org.br/ rtbeterraba.doc>03 Nov. 2008.

Kanner, J.; Harel, S.; Granit, R. Betalains: A new class of dietary cationized antioxidants. Journal of Agricultural and Food Chemistry, v.49, p.5178-5185, 2001.

Malavolta, E.; Vitti, G. C.; Oliveira, S. A. Avaliação do estado nutricional de plantas: princípios e aplicações. 2.ed. Piracicaba: Potafos, 1997. 319p.

Marques, L. F.; Medeiros, D. C.; Coutinho, O. L.; Marques, L. F. Medeiros, C. B.; Vale, L. S. Produção e qualidade da beterraba em função da adubação com esterco bovino. Revista Brasileira de Agroecologia, v.5, p.24-33, 2010.
Mesquita Filho, M. V. de; Souza, A. F.; Moita, A. W.; Ramagem, R. D. Produção comercializável e teores de $\mathrm{Cu}$ e $\mathrm{Zn}$ em cenoura em decorrência da ação residual de fósforo e composto de lixo em solo sob cerrado. Horticultura Brasileira, v.20, p.153-157, 2002.

Pereira, C. Z; Domingos, S. R.; Goto, R. Cultivo de alface tipo americana no verão, com diferentes tipos de solo. Horticultura Brasileira, v.18, p.491-492, 2000.

Puiatti, M.; Campos, J. P. de; Casali, V. W. D.; Cardoso, A. A. Sistemas de colocação do bagaço de cana-de-açúcar e do capim-gordura associados ao sulfato de amônio em inhame cv. Chinês. Horticultura Brasileira, v.10, p.13-17, 1992.

Quintela, E. D. Cultivo do feijão irrigado na região noroeste de Minas Gerais. Santo Antonio de Goiás: Embrapa Arroz e Feijão. 2005. Sistema de Produção, n ${ }^{05}$

Resende, F. V.; Souza, L. S.; Oliveira, P. S. R.; Gualberto, R. Uso de cobertura morta vegetal no controle da umidade e temperatura do solo, na incidência de plantas invasoras e na produção da cenoura em cultivo de verão. Ciência e Agrotecnologia, v.29, p.100-105, 2005.

Robinson, D. W. Mulches ornamental plantings. Author's reply. Hortscience. v.23, 1988.

Salgado, J. A. A.; Almeida, D. L.; Guerra, J. G. M.; Ribeiro, R. L. D.; Sudo, A. Balanço de nutrientes em cultivares de hortaliças sob manejo orgânico. Rio de Janeiro: Embrapa CNPAB, 1998.9p. Comunicado Técnico 21

Sampaio, R. A.; Guivara, L.; Fernandes, L. A.; Costa, C. A.; Guilherme, D. O. Produção e concentração de metais pesados em plantas de beterraba adubadas com composto de lixo urbano. Caatinga, v.21, p.83-88, 2008.

Sanches, J.; Cia, P.; Dias-Tagliacozzo, G. M.; Tivelli, S. W.; Purquerio, L. F. V. Estudo comparativo de oito cultivares de beterraba mantidas sob condição ambiente. In: Congresso Brasileiro de Olericultura, 48. 2008, Maringá, Resumos... Maringá: ABH. 2008. CD-Rom

Sediyama, M. A. N.; Santos, M. R.; Vidigal, S. M.; Santos, I. C.; Salgado, L. T. Ocorrência de plantas daninhas no cultivo de beterraba com cobertura morta e adubação orgânica. Planta Daninha, v.28, p.717-725, 2010.

Sediyama, M. A. N.; Vidigal, S. M.; Pedrosa, M. W.; Pinto, C. L. O.; Salgado, L. T. Fermentação de esterco de suínos para uso como adubo orgânico. Revista Brasileira de Engenharia Agrícola e Ambiental, v.12, p.638-644, 2008.

Smolikowski, B.; Puig, H.; Roose, E. Influence of soil protection techniques on runoff, erosion and plant production on semiarid hillsides of Cabo Verde. Agriculture, Ecosystems and Environment, v.87, p.67-80, 2001.

Tozani, R.; Lopes, H. M.; Sousa, C. M.; Silva, E. R. Manejo alternativo de plantas daninhas na cultura de beterraba. Revista Universidade Rural, Série Ciências da Vida, v.25, p.70-78, 2006. 